\title{
Nanostructured Ceramics of Potassium Sodium Bismuth Titanate: Hydrothermal Synthesis and Piezoelectric Response at Morphotropic Phase Boundary
}

\author{
Nissamuddeen Kunnath ${ }^{1,2}$, Jacob Philip ${ }^{1,3^{*}}$ \\ ${ }^{1}$ Department of Instrumentation, Cochin University of Science and Technology, Cochin, India \\ ${ }^{2}$ Department of Physics, PSMO College Tirurangadi, Tirurangadi, India \\ ${ }^{3}$ Amal Jyothi College of Engineering, Kottayam, India \\ Email: *jphilip6012@gmail.com
}

How to cite this paper: Kunnath, N. and Philip, J. (2019) Nanostructured Ceramics of Potassium Sodium Bismuth Titanate: Hydrothermal Synthesis and Piezoelectric Response at Morphotropic Phase Boundary. New Journal of Glass and Ceramics, 9, 1-14.

https://doi.org/10.4236/njgc.2019.91001

Received: May 12, 2018

Accepted: December 18, 2018

Published: December 21, 2018

Copyright (c) 2019 by authors and Scientific Research Publishing Inc. This work is licensed under the Creative Commons Attribution International License (CC BY 4.0).

http://creativecommons.org/licenses/by/4.0/

\begin{abstract}
Potassium Sodium Bismuth Titanate (KNBT) ceramics, with the general formula $(1-x) \mathrm{K}_{0.5} \mathrm{Bi}_{0.5} \mathrm{TiO}_{3}-x \mathrm{Na}_{0.5} \mathrm{Bi}_{0.5} \mathrm{TiO}_{3}$, have been synthesized following hydrothermal route, starting with solid solutions of pure perovskite nanoceramics of KBT and NBT in desired stoichiometric weight ratios, followed by sintering between $850^{\circ} \mathrm{C}$ and $1000^{\circ} \mathrm{C}$ for few hours. Pure KNBT nanoceramics with perovskite structure, having mean particle size around $30 \mathrm{~nm}$, could be obtained. Morphology of the samples is found to depend strongly on composition. A change of composition results in a phase change, as evident from X-ray structure analysis. This phase change is a result of rhombohedral to tetragonal morphotropic phase boundary (MPB) in the sample with $x$ around 0.80. Composition dependent occurrence of MPB leads to formation of needle like structures with micrometer length scales. These are typical of tetragonal lamellar structures, suggesting partial induction of tetragonal polar order from rhombohedral structure at MPB. Dielectric and piezoelectric properties, such as dielectric constant and loss, piezoelectric coefficients and figures of merit, exhibit threshold maxima in their values at the composition corresponding to MPB. These values reported for a lead-free piezoceramic, synthesized by a comparatively simple hydrothermal route, are highly promising, and comparable to well-known PZT.
\end{abstract}

\section{Keywords}

Perovskite Nanoceramics, Morphotropic Phase Boundary (MPB), Piezoceramic 


\section{Introduction}

Piezoceramics such as Lead ZirconateTitanate (PZT) are the most widely used materials for piezoelectric applications due to their high performance in terms of sensitivity, reproducibility and dynamic range. However, the presence of toxic lead in the fabrication process as well as in waste products is a crucial environmental issue [1] [2] [3]. This has generated an increasing interest in the development of lead-free piezoelectric ceramics which can replace PZT based ceramics so that lead pollution in the environment can be reduced. Compared to $\mathrm{Pb}^{2+}$, $\mathrm{Bi}^{3+}$ ions are in an isoelectronic state and also show a lone pair effect. This has encouraged scientists to investigate and develop alkali metal titanates like Bismuth Titanate as an alternative to PZT ceramics. Layer structured materials like Bismuth Titanate with Aurivillius phase have attracted great deal of attention in recent years from both theoretical and applications points of view as many of them offer excellent ferro and piezoelectric properties [4] [5] [6] [7]. However, lack of any morphotropic phase boundary (MPB) and consequent occurrence of thresholds in piezoelectric response make them less attractive for piezoelectric applications [8].

Detailed description of the origin and occurrence of MPB in piezoceramics and its contribution to piezoelectric properties is well documented in literature [9] [10]. MPB is a phase boundary existing in ferroelectrics in which a change of composition results in a change of phase. In PZT, the electro-mechanical properties show a maximum over a compositional range around its MPB due to increase in the number of possible spontaneous polarization directions for the composition near MPB. This is the result of the co-existence of rhombohedral and tetragonal phases in the structure of PZT. A good number of materials that exhibit MPB structure have been synthesized by different authors, and their piezoelectric, elastic and dielectric properties have appeared in literature [10] [11]. Of late, papers have appeared on the synthesis and properties of many lead-free composite ceramics as well [12].

Sodium Bismuth Titanate (NBT), first synthesized by Smolenskii et al., is a perovskite-type relaxor ferroelectric with a Curie temperature of $320^{\circ} \mathrm{C}$ [13]. It has a rhombohedral structure at room temperature, and shows a relatively large remnant polarization $\left(p_{r}=38 \mu \mathrm{C} / \mathrm{cm}^{2}\right)$. However, it is difficult to electrically pole NBT due to a high coercive field $\left(E_{c}=7.3 \mathrm{KV} / \mathrm{mm}\right.$ ), making it difficult to obtain the desirable piezoelectric properties. In addition, unlike PZT ceramics, NBT as such has no MPB occurring in it [14] [15]. Though NBT as such is not piezoelectric, solid solutions like Potassium Sodium Bismuth Titanate (KNBT) possess an MPB structure. Moreover, the KNBT composite can easily be poled and piezoelectricity induced in it. This material can be produced by forming a binary mixture of Sodium Bismuth Titanate (NBT) and Potassium Bismuth Titanate (KBT) in the desired proportions.

Traditionally KNBT powders are prepared following the solid state reaction route, with the starting materials being oxides or carbonates of $\mathrm{Bi}, \mathrm{K}, \mathrm{Na}$ and $\mathrm{Ti}$ 
having particle sizes in micrometer or sub micrometer ranges. Generally, this kind of reaction takes place when the components of the mixture have sufficient thermal energy to overcome the atomic/ionic diffusion barriers and hence are possible only at very high perovskite phase forming temperatures. In most cases the resultant powders are not nanocrystalline; they undergo drastic agglomeration and yield inhomogeneous particle sizes as a result of high temperature treatment, making them unfit for enhancing further the dielectric or piezoelectric properties for high performance applications.

In contrast to the solid-state reaction route outlined above, hydrothermal synthesis has the potential to produce highly pure and homogeneous metal oxide powders with good control over their stoichiometry, crystallite size and morphology [16] [17]. Recently, utilization of such well-defined metal oxide powders as precursors for piezoelectric ceramics has received much attention, because high performance ceramics close to a MPB have been obtained by texturetreatment [18] or template grain growth [19] utilizing them. As a novel method for preparation of oxide nanopowders, hydrothermal method has the advantage of delivering well-controlled morphology, high purity and narrow particle size distribution for the prepared powders [20].

In this work we report a novel method for the synthesis of solid solutions of Potassium sodium bismuth titanate (KNBT), with stoichiometric formula $(1-\mathrm{x}) \mathrm{K}_{0.5} \mathrm{Bi}_{0.5} \mathrm{TiO}_{3}-\mathrm{xNa}_{0.5} \mathrm{Bi}_{0.5} \mathrm{TiO}_{3}$, by sintering solid solutions of Potassium Bismuth Titanate (KBT) and Sodium Bismuth Titanate (NBT) nanoceramics, synthesized following hydrothermal route at a temperature below $200^{\circ} \mathrm{C}$, which is much lower than needed for other methods. The prepared KNBT nanopowders have been characterized for their structure by X-ray diffraction and morphology by Scanning electron microscopy. The dielectric and piezoelectric properties are investigated, and are found to be superior to the corresponding compositions prepared following traditional solid state reaction methods. The piezoelectric coefficients and figures of merit have also been determined. It is found that the composition with $x=0.8$ exhibits features that correspond to a MPB structure. It is also found that the piezoelectric properties exhibit threshold maxima in their values at the composition corresponding to the above MPB structure. The relevant properties are compared with those of PZT so as to explore the possibilities of replacing PZT with this lead-free ceramic. It is seen that the above composition of this lead-free composite ceramic, synthesized following a relatively simple procedure, exhibits piezoelectric properties comparable to PZT type ceramics.

\section{Experimental}

\subsection{Composite Preparation}

Analytical grade Bismuth nitrate pentahydrate $\left(\mathrm{Bi}\left(\mathrm{NO}_{3}\right)_{3} \cdot 5 \mathrm{H}_{2} \mathrm{O}\right.$, Alpha Aesar, 98\%), Titanium dioxide $\left(\mathrm{TiO}_{2}\right.$, Fisher Scientific, 98\%), Potassium hydroxide $(\mathrm{KOH})$ and Sodium hydroxide $(\mathrm{NaOH})$ were used as precursors for the hydro- 
thermal synthesis of Potassium and Sodium Bismuth titanates. The alkaline hydroxides were used to adjust the $\mathrm{p}^{\mathrm{H}}$ values of the solutions. A stoichiometric ratio of 2 for Titanium to Bismuth $(\mathrm{Ti} / \mathrm{Bi}=2)$ was employed in the starting materials of the reaction. Initially $\mathrm{KBT}$ and $\mathrm{NBT}$ nanopowders were prepared separately following the hydrothermal route.

The procedures followed for the preparation of KBT or NBT nanoparticles were as follows. First, Bismuth nitrate was dissolved in $\mathrm{CO}_{2}$-free distilled water under vigorous stirring, in to which the corresponding alkali metal hydroxide was added, followed by the addition of Titanium dioxide. After stirring vigorously for about 2 hours, a thin yellow homogeneous solution was formed. The concentrations of $\mathrm{Ti}^{4+}$ and $\mathrm{Bi}^{3+}$ in the suspension were 0.25 and $0.50 \mathrm{~mol} / \mathrm{dm}^{3}$ respectively, and the alkali metal hydroxide concentration was adjusted to 12 $\mathrm{mol} / \mathrm{dm}^{3}$. The as-prepared mixture was poured in to a Teflon lined autoclave and was then subjected to hydrothermal treatment at $165^{\circ} \mathrm{C}$ at a comparatively low pressure of 1.5 bars for 72 hours. The so-obtained product was collected and the sediments were washed three times by dispersing in $\mathrm{CO}_{2}$-free distilled water followed by centrifuging. The raw powders were then dried overnight at an ambient temperature of $75^{\circ} \mathrm{C}$. The KBT and NBT powders thus prepared were mixed in desired weight ratios and pelletized, with Polyvinyl alcohol used as a binder, to get different solid solutions of KNBT with the general formula $(1-\mathrm{x}) \mathrm{K}_{0.5} \mathrm{Bi}_{0.5} \mathrm{TiO}_{3}-\mathrm{xNa}_{0.5} \mathrm{Bi}_{0.5} \mathrm{TiO}_{3}$, where $x=0$, 0.20, 0.25, 0.33, 0.50, $0.75,0.80,0.85$ and 1.0. Thin discs of diameter $9 \mathrm{~mm}$ and thickness $1 \mathrm{~mm}$ were calcined at $600^{\circ} \mathrm{C}$ and then sintered at $50^{\circ} \mathrm{C}$ intervals between $850^{\circ} \mathrm{C}$ and $1000^{\circ} \mathrm{C}$ for duration of half-hour each. After heat treatment of the samples, the dry weights of the pellets were measured with a balance and the bulk densities of the sintered samples were determined.

\subsection{X-Ray Diffraction (XRD) Measurement}

The crystalline phases of the prepared composite ceramic discs were determined using X-ray powder diffractometry in the $\theta-2 \theta$ mode with $\mathrm{Cu}-\mathrm{K} \alpha$ radiation of wave length $1.5406 \AA$ (Bruker make, D8 Advance). The lattice parameters (a, b and c) and the unit cell volume (V) were calculated from the obtained XRD data using the MAUD programme.

\subsection{Scanning Electron Microscopy (SEM) with Energy Dispersive XRay (EDX) Measurement}

Scanning Electron Microscopy (SEM) with Energy Dispersive X-Ray measurement has been used to identify and characterize the matrix. The SEM images of all the samples were recorded with a scanning electron microscope (Jeol make, Model $6390 \mathrm{LV}$ ) to examine the morphology of the matrix and homogeneity. Energy Dispersive X-ray (EDX) was specifically used to obtain a qualitative information on the full elemental composition of any unknown contaminant in the matrix. 


\subsection{Dielectric and Piezoelectric Measurements}

The KNBT ceramics were cut and polished for various physical and electrical measurements reported in this work. Silver paste was used as the electrode for the measurement of dielectric and piezoelectric properties of the samples. The dielectric properties were measured using an Impedance analyzer (Hioki make, IM 3570) with the thinned sample mounted as dielectric medium in parallel-plate capacitor geometry.

The piezoelectric charge coefficient $d_{33}$ was determined with a conventional Berlin court Piezo D33 Test System (Piezotest make, PM300). The specimens for piezoelectric measurements were polled by applying a DC electric field of 2 $\mathrm{kV} / \mathrm{mm}$ for 10 minutes in a stirred silicone bath at $150^{\circ} \mathrm{C}$.

The piezoelectric coefficient $d_{33}$, also known as the piezoelectric strain coefficient, is a very important parameter for piezoelectric actuators. There are, however, other important parameters also to be considered for such materials [21]. The internal polarization for a material is not an easy property to measure. In many materials, the measured variable is the voltage or the electric field $(E)$ that is induced due to an applied stress $(\sigma)$. The relationship between the field and stress is given by the piezoelectric voltage coefficient $g$, given as [22] [23],

$$
E=g \sigma
$$

Taking in to account the relationship between electric field and polarization it can readily be shown that,

$$
g=d / \varepsilon \varepsilon_{0}
$$

The above equations are in fact simplified forms of the corresponding tensor relations, which holds good for either homogeneous materials or along the principal axes of the crystal. Both strain and voltage piezoelectric coefficients give the magnitude of the effect. However, the efficiency of the material in converting electrical energy to mechanical energy and vice-versa is given by the electro-mechanical coupling factor which is the ratio of the stored electric energy to the input energy. It can be shown that the electromechanical coupling factor $k^{2}$ is related to the strain constant $d$ and the dielectric constant $\varepsilon_{0}$ as

$$
k^{2}=d^{2} / \varepsilon \varepsilon_{0}
$$

\section{Results and Discussions}

\subsection{Bulk Density Measurements}

The variation of bulk mass density of KNBT samples as a function of NBT concentration is shown in Figure 1. The theoretical density of KBT is $5.929 \mathrm{~g} / \mathrm{cc}$ and that of NBT is $5.568 \mathrm{~g} / \mathrm{cc}$. The theoretical density of various KNBT composition are calculated as the weighted average of their respective KBT and NBT contributions. So, as expected, solid solutions of KNBT composites show a corresponding mean values. Moreover, as is evident from Figure 1, the bulk densities of the samples show good agreement with the corresponding theoretical values and the nature of variation are exactly identical. 


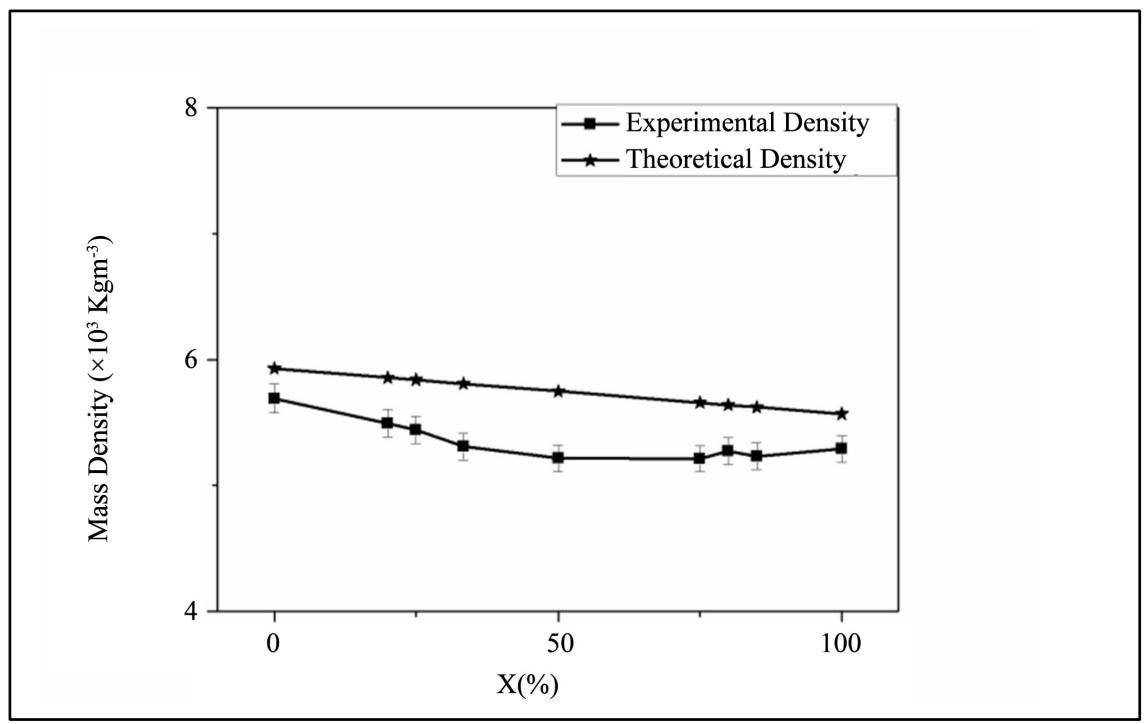

Figure 1. Variation of mass density with percentage concentration of NBT (x).

\subsection{Powder XRD Measurements}

During synthesis of metallic oxide nanoparticles following hydrothermal route, hydroxide ion concentration is a decisive factor that determines the formation rate as well as crystalline structure of solid particles [15] [24]. In the case of complex perovskite fine particles like KBT and NBT, initial $\mathrm{p}^{\mathrm{H}}$ value strongly influences the crystalline structure and shape of the particles [19] [20]. It is found that a highly alkaline condition, with $\mathrm{p}^{\mathrm{H}}$ init $>10$, is essential for the formation of NBT in single phase. Decrease in $\mathrm{p}^{\mathrm{H}}$ init induces formation of $\mathrm{Bi}_{2} \mathrm{Ti}_{2} \mathrm{O}_{7}[24]$ and metallic Bismuth [25]. Figure 2 shows the XRD patterns of hydrothermally treated pure $\mathrm{K}_{0.5} \mathrm{Bi}_{0.5} \mathrm{TiO}_{3},(1-\mathrm{x}) \mathrm{K}_{0.5} \mathrm{Bi}_{0.5} \mathrm{TiO}_{3}-\mathrm{xNa}_{0.5} \mathrm{Bi}_{0.5} \mathrm{TiO}_{3}$ (with $\mathrm{x}=0.20$, $0.25,0.33,0.50,0.75,0.80$ and 0.85 ) and pure $\mathrm{Na}_{0.5} \mathrm{Bi}_{0.5} \mathrm{TiO}_{3}$ nanopowders, all sintered at $1000^{\circ} \mathrm{C}$ for three hours. As can be seen from the XRD patterns, well crystallized phases are obtained for the samples and the particle sizes estimated using Scherer's formula are found to be around $18 \mathrm{~nm}, 28 \mathrm{~nm}, 29 \mathrm{~nm}, 31 \mathrm{~nm}, 30$ $\mathrm{nm}, 32 \mathrm{~nm}, 30 \mathrm{~nm}, 29 \mathrm{~nm}$, and $30 \mathrm{~nm}$ respectively for the above samples. The presence of broad diffraction peaks in the case of pure KBT, pure NBT and samples with weight ratio adjusted from 0.25 to 0.75 between KBT and NBT in the solid solution, and with $\mathrm{x}=0.85$ can be assigned as due to the formation of KNBT phase with a rhombohedral crystal structure belonging to $R 3 \mathrm{C}$ space group (JCPDS File No. 01-070-9850) as a major phase [26]. However, in the case of $(1-\mathrm{x}) \mathrm{K}_{0.5} \mathrm{Bi}_{0.5} \mathrm{TiO}_{3}-\mathrm{xNa}_{0.5} \mathrm{Bi}_{0.5} \mathrm{TiO}_{3}$, with $\mathrm{x}=0.80$, the diffraction peaks are sharp, and using JCPDS matching it is found that the diffraction peaks of this structure correspond to a tetragonal phase belonging to the space group $P 4 \mathrm{~mm}$ with lattice parameters $a=b=3.761 \AA$ and $c=6.112 \AA$. The additional peaks corresponding to tetragonal phase are also found to appear for this composition. This clearly indicates a change in phase resulting from a change of concentration, which corresponds to a MPB. The composition range of MPB has also been determined using XRD patterns, which show the coexistence of rhombohedral 
$(R 3 c)$ and tetragonal $(P 4 \mathrm{~mm})$ structures in uneven proportion at the composition with $\mathrm{x}=0.80$.

The lattice parameters ( $a, b$ and $c$ ) and the unit cell volume (V) were calculated from the obtained XRD data using the MAUD programme for all the samples and are shown in Table 1 and Figure 3 . The unit cell volume initially shows an increase and then falls slightly for composition with $\mathrm{x}=0.5$ and then remains almost constant. This is reflected in the XRD pattern also (Figure 2) as a shift in the peak position for the corresponding compositions. Compared to pure NBT and KBT the lattice parameters $a, b$ and $c$ more or less remain equal and constant for composition with $\mathrm{x} \leq 0.5$. However, for the composition with $\mathrm{x}>0.5$, a and $b$ fall slightly whereas $c$ increases considerably. This increase is at its peak for the composition with $\mathrm{x}=0.8$ at a value of $6.112 \mathrm{~A}^{0}$. This indicates that due to the coexistence of $\mathrm{NBT}$ and $\mathrm{KBT}$ in different weight ratios, the structure starts changing from rhombohedral to tetragonal from $\mathrm{x}=0.5$ onwards and is distinctly in tetragonal phase for composition with $\mathrm{x}=0.8$. The tetragonal distortion is also evaluated as shown in Table 1. It is found that the rhombohedral distortion ( $b / a)$ almost remains constant as unity for all compositions whereas tetragonal strain constant $(c / a)$, though remains almost unity for $\mathrm{x} \leq 0.5$, start increasing up to a maximum of almost $63 \%$ at composition with $\mathrm{x}=0.8$. This further indicates that a change of composition result in a change of phase from rhombohedral to tetragonal resulting in an MPB at the composition with $\mathrm{x}=0.8$. It may also be noted here that the unit cell volume though constant for compositions with $\mathrm{x}>0.5$ it shows a slight increase for composition with $\mathrm{x}=0.75$. This is resulted from the simultaneous fall of the lattice parameters $a$ and $b$ along with anelongation for the lattice parameter $c$, as this composition is reached. However the tetragonal strain constant (c/a) still increase to show a maximum value at $\mathrm{x}=$ 0.8. Further, this modification results in lattice distortion which is supposed to lead to enhanced polarizability [12] [27] [28]. It is anticipated to be beneficial to the dielectric and piezoelectric properties of the crystal [29].

Table 1. Lattice parameters of KNBI ceramics.

\begin{tabular}{|c|c|c|c|c|c|c|}
\hline & & $\begin{array}{c}\text { Lattice } \\
\text { Parameters }\end{array}$ & & & & \\
\hline & $\mathrm{a}(\mathrm{A} 0)$ & $\mathrm{b}(\mathrm{A} 0)$ & $c(\mathrm{~A} 0)$ & V (A03) & $\mathrm{b} / \mathrm{a}$ & $\mathrm{c} / \mathrm{a}$ \\
\hline 0.00 & $3.973 \pm 0.0008$ & $3.989 \pm 0.0007$ & $3.989 \pm 0.0007$ & 63.206 & 1.004 & 1.004 \\
\hline 0.20 & $4.241 \pm 0.0010$ & $4.241 \pm 0.0007$ & $4.241 \pm 0.0008$ & 76.268 & 1.000 & 1.000 \\
\hline 0.25 & $4.243 \pm 0.0008$ & $4.245 \pm 0.0005$ & $4.247 \pm 0.0005$ & 76.502 & 1.001 & 1.001 \\
\hline 0.33 & $4.119 \pm 0.0006$ & $4.123 \pm 0.0005$ & $4.587 \pm 0.0006$ & 77.903 & 1.001 & 1.113 \\
\hline 0.50 & $4.197 \pm 0.0007$ & $1.199 \pm 0.0004$ & $4.957 \pm 0.0010$ & 87.342 & 1.000 & 1.181 \\
\hline 0.75 & $4.022 \pm 0.0007$ & $4.026 \pm 0.0010$ & $5.548 \pm 0.0006$ & 89.823 & 1.001 & 1.380 \\
\hline 0.80 & $3.761 \pm 0.0007$ & $3.761 \pm 0.0006$ & $6.112 \pm 0.0005$ & 86.936 & 1.000 & 1.625 \\
\hline 0.85 & $3.988 \pm 0.0008$ & $3.989 \pm 0.0007$ & $5.524 \pm 0.0007$ & 87.85 & 1.000 & 1.385 \\
\hline 1.00 & $4.236 \pm 0.00009$ & $4.238 \pm 0.0006$ & $4.328 \pm 0.0006$ & 77.696 & 1.000 & 1.022 \\
\hline
\end{tabular}




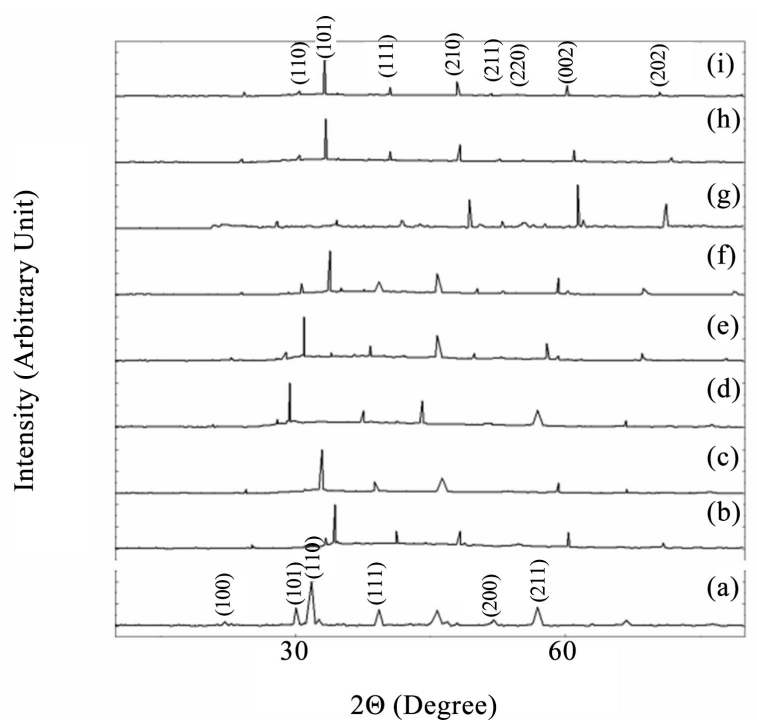

Figure 2. XRD patterns of hydrothermally synthesized Potassium Sodium Bismuth Titanates, $(1-\mathrm{x}) \mathrm{K}_{0.5} \mathrm{Bi}_{0.5} \mathrm{TiO}_{3}-\mathrm{xNa}_{0.5} \mathrm{Bi}_{0.5} \mathrm{TiO}_{3}$ with $\mathrm{x}=0$ (pure $\mathrm{KBT}$ ) (a), 0.20 (b), 0.25 (c), 0.33 (d), 0.50 (e), 0.75 (f), $0.80(\mathrm{~g}), 0.85$ (h) and 1.00 (pure NBT) (i), all sintered between $850^{\circ} \mathrm{C}$ and $1000^{\circ} \mathrm{C}$ for three hours.

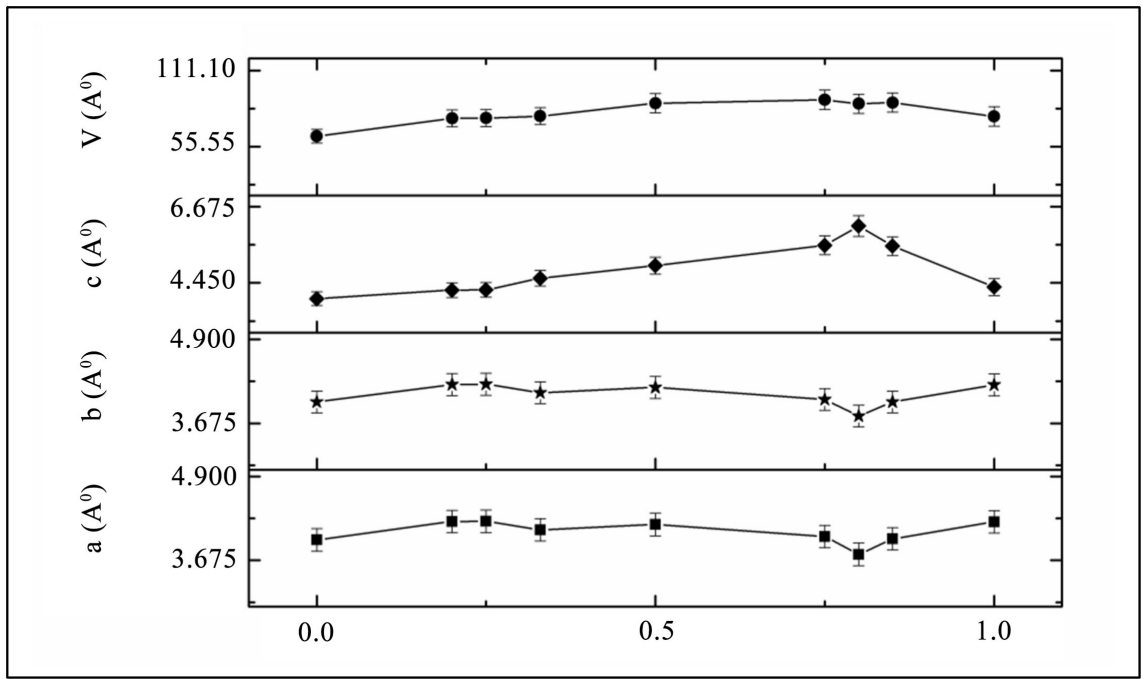

Figure 3. Variation of lattice parameters with percentage concentration of NBT(x).

\subsection{Microstructure Studies}

SEM images of as-prepared samples are shown in Figure 4. Morphology and mean sizes of the resulting particles undergo drastic changes with variation in concentration ratio between KBT and NBT in the composite samples. The nearly spherical fine particles are formed in the case of pure KBT and pure NBT (Figure 4(a) and Figure 4(i)), whereas rod-like cubic structures start forming as NBT concentration is increased in the KNBT sample (Figures $4(\mathrm{~d})-(\mathrm{h})$ ). As can be seen from Figure $4(\mathrm{~g})$, this rod-like structure formation is at its top end corresponding to the composition $(1-\mathrm{x}) \mathrm{K}_{0.5} \mathrm{Bi}_{0.5} \mathrm{TiO}_{3}-\mathrm{xNa}_{0.5} \mathrm{Bi}_{0.5} \mathrm{TiO}_{3}$, with 


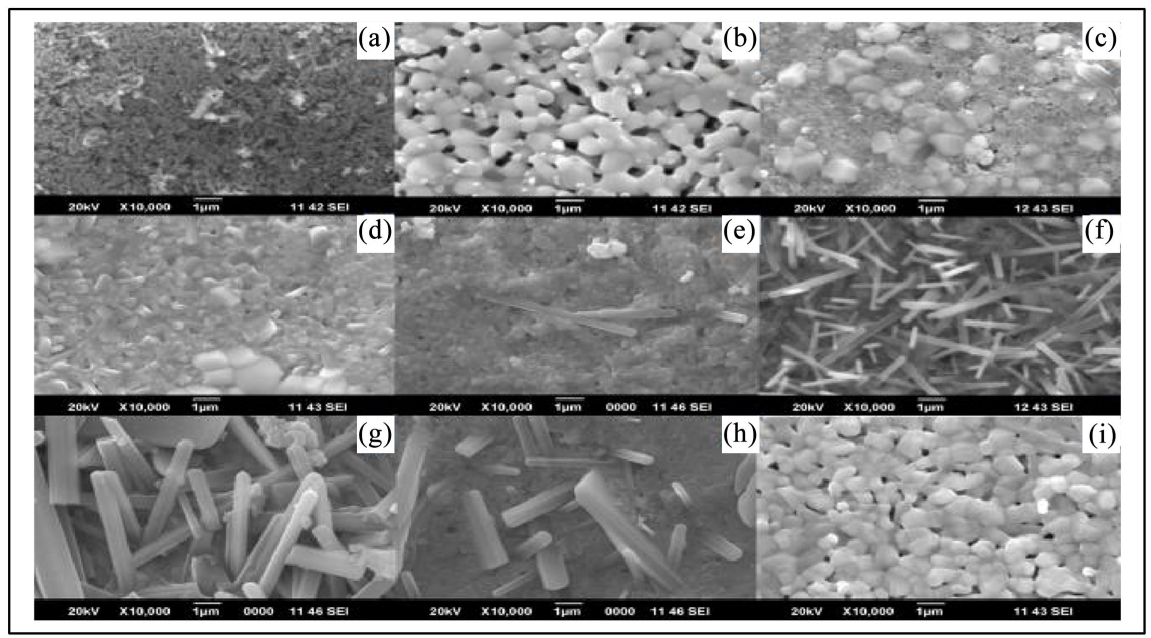

Figure 4. SEM images of hydrothermally synthesized Sodium Potassium Bismuth Titanates, $(1-\mathrm{x}) \mathrm{K}_{0.5} \mathrm{Bi}_{0.5} \mathrm{TiO}_{3}-\mathrm{xNa}_{0.5} \mathrm{Bi}_{0.5} \mathrm{TiO}_{3}$ with $\mathrm{x}=0$, pure $\mathrm{KBT}(\mathrm{a}), 0.20$ (b), 0.25 (c), $0.33(\mathrm{~d}), 0.50(\mathrm{e}), 0.75(\mathrm{f}), 0.80(\mathrm{~g}), 0.85(\mathrm{~h})$ and 1.00 , pure NBT (i), all sintered at $1000^{\circ} \mathrm{C}$ for a duration of three hours.

$\mathrm{x}=0.80$, whereas this rod-like structure starts to disappear for the composition $(1-\mathrm{x}) \mathrm{K}_{0.5} \mathrm{Bi}_{0.5} \mathrm{TiO}_{3}-\mathrm{xNa}_{0.5} \mathrm{Bi}_{0.5} \mathrm{TiO}_{3}$, with $\mathrm{x}=0.85$ and disappear completely for pure NBT. The average grain sizes of the ceramic particles have been calculated by counting 100 particles taken from SEM images, and the mean sizes are found to be around $125 \mathrm{~nm}, 344 \mathrm{~nm}, 234 \mathrm{~nm}, 240 \mathrm{~nm}, 186 \mathrm{~nm}, 220 \mathrm{~nm}, 350 \mathrm{~nm}, 210$ $\mathrm{nm}$, and $320 \mathrm{~nm}$ respectively for pure KBT, $(1-\mathrm{x}) \mathrm{K}_{0.5} \mathrm{Bi}_{0.5} \mathrm{TiO}_{3}-\mathrm{xNa}_{0.5} \mathrm{Bi}_{0.5} \mathrm{TiO}_{3}$, with $\mathrm{x}=0.20,0.25,0.33,0.50,0.75,0.80,0.85$ and pure NBT. In the case of the composition with $\mathrm{x}=0.80$ the rod-like structures have an average diameter around $450 \mathrm{~nm}$ and length as high as a few micrometers.

Among the various KNBT ceramics the grain size is found to be minimum in the case of pure KBT and it is found to increase as the concentration of NBT is increased. It appears that higher concentration of KBT in the composite sample generally inhibits the grain growth; however, a considerable population of NBT in the sample enhances grain growth as can be seen in Figures 4(d)-(h). In such NBT dominant ceramics the domains of most of the grains are lamellar or needle-shaped and is an indicator of the formation of tetragonal domains, and this result is in agreement with the studies reported earlier by Octonicar et al. [30]. A more detailed discussion on the actual mechanism of domain formation close to MPB requires neutron scattering or selected area electron diffraction studies of the compositions.

\subsection{Dielectric Characterization}

The dielectric constants and dielectric losses of different samples show a normal variation with frequency for phase pure KBT and NBT as well as for different compositions of KNBT, as is evident from Figure 5 and Figure 6. However, the magnitude of dielectric constant, instead of following a mean field approximation, increases in a nonlinear manner for KNBT samples with increase in Sodium 


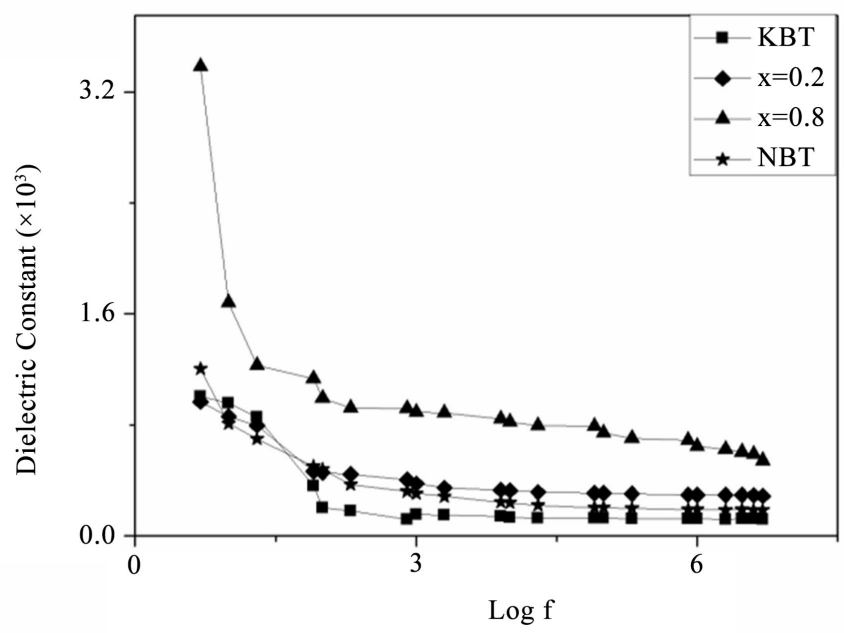

Figure 5. Variation of Dielectric constant with frequency for different samples listed in the inset.

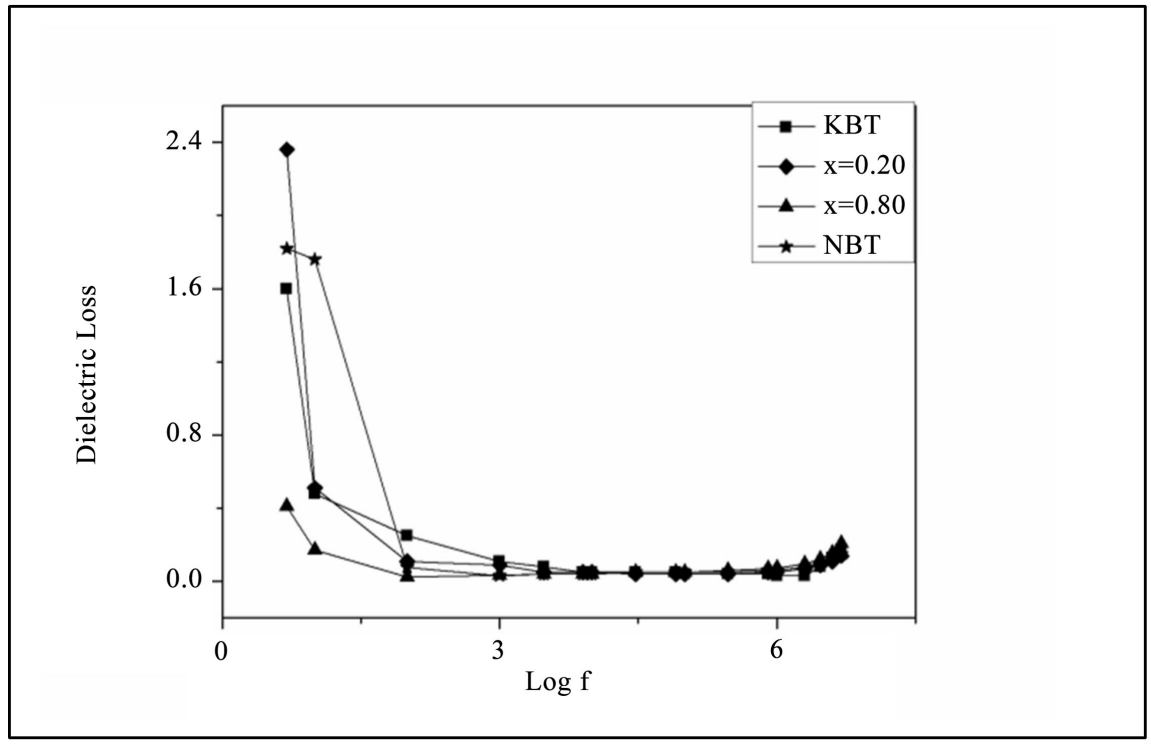

Figure 6. Variations of dielectric loss with frequency for different samples listed in the inset.

content. This is shown in Figure 7. It is clear that the properties peak to a maximum for the composition with $x=0.80$, and is assigned to be as due to this composition being close to a Morphotropic Phase Boundary (MPB) where the ions are subjected to comparatively large remnant polarization.

\subsection{Piezoelectric Measurement}

Owing to the presence of MPB structure in KNBT ceramics at the composition with $x=0.80$, the relevant piezoelectric properties of all the samples have been determined. The $d_{33}$ coefficients of all the prepared compositions have been 
measured and the piezoelectric figures of merit - the piezoelectric voltage coefficient $g_{33}$ and the electro-mechanical coupling coefficient $K^{2}$-have been evaluated using Equations (2) and (3). It is important to note that though the Potassium sodium bismuth titanates with aurivillius phase, prepared following conventional solid state reaction route offer a $d_{33}$ coefficient about $20 \mathrm{pC} / \mathrm{N}[20]$, KNBT ceramics synthesized following hydrothermal route described above offer a much higher piezoelectric $d_{33}$ coefficient of about $40 \mathrm{pC} / \mathrm{N}$. Figure 8 , shows the variations of the various piezoelectric figures of merit with concentration of $\mathrm{NBT} / \mathrm{KBT}$ for these samples. It is clear from the figure that these properties are at their threshold maxima at the composition corresponding to $x=0.80$, which corresponds to MPB. It may also be noted that the $d_{33}$ coefficient for this composition increases to about $88 \mathrm{pC} / \mathrm{N}$.

Table 2 shows a comparison of the piezoelectric properties of PZT with those of KNBT ceramics at the threshold corresponding to $x=0.80$ (MPB). Values available in literature for commercially available PZT-4 have been used for comparison [25] [26] [30]. These values of PZT-4 are comparable to the corresponding values for PZT at MPB [31]. A comparison of the values of dielectric and piezoelectric properties shows that the dielectric constants are of the same order of magnitude while the dielectric loss is smaller for KNBT. The extensional strain coefficient $d_{33}$ is only about $50 \%$ for KNBT, while the extensional voltage coefficient $g_{33}$ is higher for it. Again, the electro-mechanical coupling coefficient $\mathrm{K}^{2}$ is much higher for KNBT. So we see that the lead-free KNBT, synthesized following comparatively simple hydrothermal route, offers a promising alternative to PZT for piezoelectric applications.

Further, it can be anticipated that KNBT ceramics with still smaller grain sizes

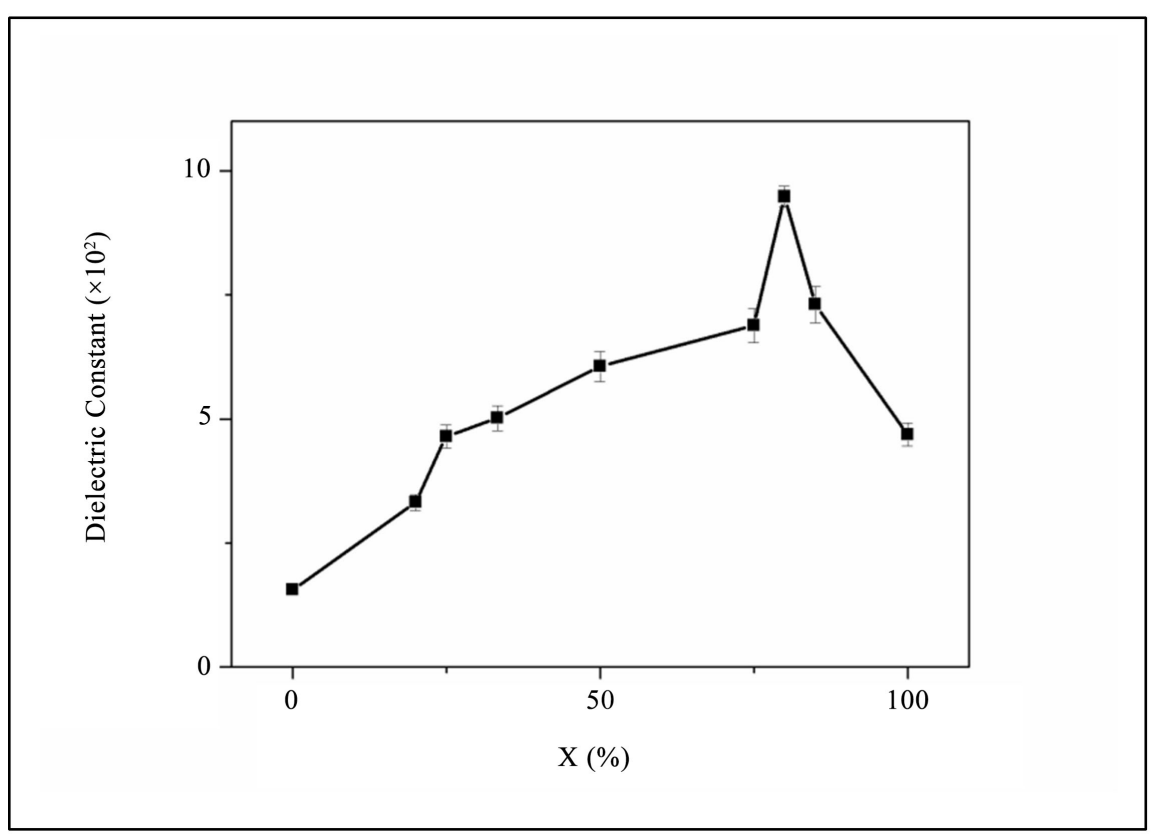

Figure 7. Variation of Dielectric constant with percentage concentration of NBT $(x)$ at 3 $\mathrm{kHz}$. 


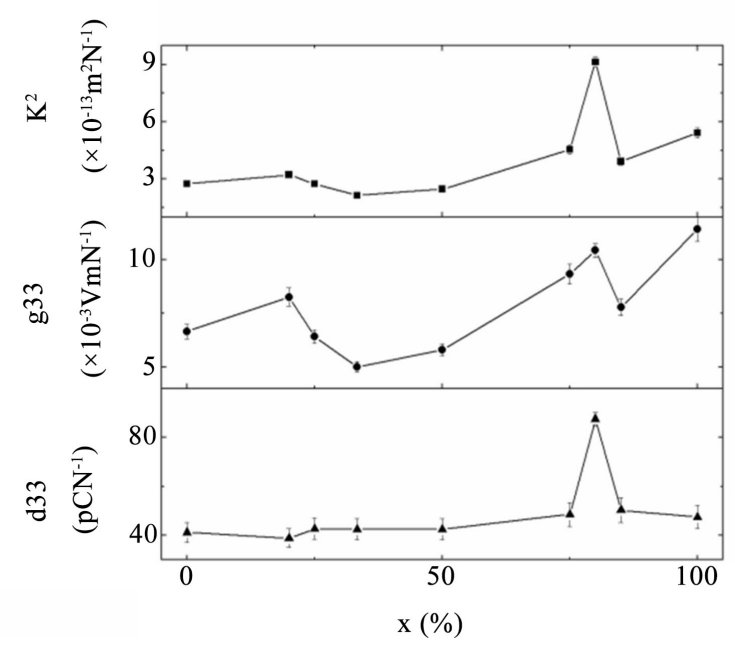

Figure 8. Variations of Piezoelectric figures of merit with percentage concentration of $\operatorname{NBT}(\mathrm{x})$.

Table 2. Comparison of dielectric and piezoelectric properties of PZT-4 and KNBT with MPB structure at room temperature.

\begin{tabular}{cccccc}
\hline Sample/Property & $\begin{array}{c}\text { Dielectric } \\
\text { Constant } \varepsilon_{\mathrm{r}} \\
(\text { at 1 Kz) }\end{array}$ & $\begin{array}{c}\text { Dielectric } \\
\text { loss (tan } \delta)\end{array}$ & $\begin{array}{c}\mathrm{d} 33 \\
\left(\times 10^{-12}\right) \\
\mathrm{CN}^{-1}\end{array}$ & $\begin{array}{c}\mathrm{g} 33\left(\times 10^{-3}\right) \\
\left(\mathrm{VmN}^{-1}\right)\end{array}$ & $\begin{array}{c}\text { Electromechanical } \\
\text { Coupling Coefficient, } \\
\mathrm{K}^{2}\end{array}$ \\
\hline $\begin{array}{c}\text { PZT-4 } \\
\text { Reference [31] }\end{array}$ & 1400 & 0.05 & 225 & 8.5 & 0.35 \\
$\begin{array}{c}\text { KNBT with MPB } \\
\text { structure }\end{array}$ & $891 \pm 0.031$ & $0.031 \pm 0.002$ & $88 \pm 5$ & $10.4 \pm 0.5$ & $0.91 \pm 0.05$ \\
\hline
\end{tabular}

(which could be controlled by optimization of sintering conditions)may lead to further enhancement in their piezoelectric properties [32]. However, more detailed investigations are required to reveal the dependence of these properties on the particle size and morphology for the development of potential lead-free piezoceramics for practical applications.

\section{Conclusion}

Different compositions of KNBT nanoceramics have been prepared from KBT and NBT nanopowders following hydrothermal method at comparatively low temperatures. The method offers a novel and simple route for the synthesis of high quality ceramics in powder form with particle dimensions in nanometer scales. Analysis shows that the composition around $\mathrm{K}_{0.2} \mathrm{Na}_{0.8} \mathrm{BiTiO}_{3}$ undergoes a microstructural phase change from rhombohedral to tetragonal structure, which is identified as a morphotropic phase boundary. The piezoelectric properties show threshold maxima at this composition, and are comparable to the wellknown PZT. The results reveal the potential of the procedure followed in this work for the development of lead-free piezoelectric nanoceramics to replace PZT for the development of sensors and actuators. 


\section{Conflicts of Interest}

The authors declare no conflicts of interest regarding the publication of this paper.

\section{References}

[1] Uchino, K. (2000) Ferroelectric Devices. Marcel Dekker, New York.

[2] Nair, K.M. (Ed.) (2004) Proceedings of the High Strain Piezoelectric Materials, Devices and Applications, and Advanced Dielectric Materials and Multilayer Electric Devices Symposia, Westerville, American Ceramic Society.

[3] Lupascu, D.C. and Rodel, J. (2005) Fatigue in Bulk Lead Zirconate Titanate Actuator Materials. Advanced Engineering Materials, 7, 882-898.

[4] Yan, H.X., Zhang, H.T., Ubic, R., Reece, M.J., Liu, J., Shen, Z.J. and Zhang, Z. (2005) A Lead-Free High Curie Point Ferroelectric Ceramic, $\mathrm{CaBi}_{2} \mathrm{Nb}_{2} \mathrm{O}_{9}$. Advanced Materials, 17, 1261-1267.

[5] Park, B.H., Kang, B.S., Bu, S.D., Noh, T.W., Lee, J. and Jo, W. (1999) Lanthanum-Substituted Bismuth Titanate for Use in Non-Volatile Memories. Nature, 401, 682-685.

[6] Chon, U., Jang, H.M., Kim, M.G. and Chang, C.H. (2002) Layered Perovskites with Giant Spontaneous Polarization for Non-Volatile Memories. Physical Review Letters, 89, 087601.

[7] Cohen, R.E. (1992) Origin of Ferroelectricity in Perovskite Oxides. Nature, 358, 136-138.

[8] Gao, J., Hu, X., Liu, Y., Wang, Y., Ke, X., Wang, D., Zhong, L. and Ren, X. (2017) Ferroelectric Domain Walls Approaching Morphotropic Phase Boundary. The Journal of Physical Chemistry C, 121, 2243-2250.

[9] Ahart, M., Somayazulu, M., Cohen, R.E., Ganesh, P., Dera, P., Mao, H.-K., Hemley, R.J., Ren, Y., Liermann, P. and Wu, Z. (2008) Origin of Morphotropic Phase Boundaries in Ferroelectrics. Nature, 451, 545-548.

[10] Wu, J., Xiao, D. and Zhu, J. (2015) Potassium-Sodium Niobate Lead-Free Piezoelectric Materials: Past, Present and Future of Phase Boundaries. Chemical Reviews, 115, 2559-2595.

[11] Jo, W., Daniels, J.E., Jones, J.L., Tan, X., Thomas, P.A., Damjanovic, D. and Rödel, J. (2011) Evolving Morphotropic Phase Boundary in Leadfree $\left(\mathrm{Bi}_{1 / 2} \mathrm{Na}_{1 / 2}\right)$ $\mathrm{TiO}_{3}-\mathrm{BaTiO}_{3}\left(\mathrm{Bi}_{1 / 2} \mathrm{Na}_{1 / 2}\right) \mathrm{TiO}_{3}-\mathrm{BaTiO}_{3}$ Piezoceramics. Journal of Applied Physics, 109, 014110-7.

[12] Wang, C.-M., Zhao, L., Wang, J.-F., et al. (2009) Piezoelectric and Dielectric Properties of Cerium-Modified Aurivillius Type $\mathrm{K}_{0.5} \mathrm{La}_{0.5} \mathrm{Bi}_{4} \mathrm{Ti}_{4} \mathrm{O}_{15}$ Ceramics. Materials Chemistry and Physics, 114, 1004-1007.

[13] Smolenskii, G.A., Isupov, V.A., Agranovskaya, A.I. and Krainik, N. (1961) New Ferroelectrics of Complex Composition. Soviet Physics, Solid State, 2, 2651-2654.

[14] Sasaki, A., Chiba, T., Mamiya, Y. and Otsuki, E. (1999) Dielectric and Piezoelectric Properties of $\left(\mathrm{Bi}_{0.5} \mathrm{Na}_{0.5}\right) \mathrm{TiO}_{3}-\left(\mathrm{Bi}_{0.5} \mathrm{~K}_{0.5}\right) \mathrm{TiO}_{3}$ Systems. Japanese Journal of Applied Physics, 38, 5564-5567. https://doi.org/10.1143/JJAP.38.5564

[15] Rodel, J., Jo, W., Seifert, K.T.P., Anton, E.-M., Granzow, T. and Damjanovic, D. (2009) Perspective on the Development of Lead-Free Piezoceramics. Journal of the American Ceramic Society, 92, 1153-1177.

[16] Li, Y.M., Chen, W., Zhou, J., Xu, Q., Sun, H.J. and Liao, M.S. (2005) Dielectric and Ferroelectric Properties of Lead Free $\mathrm{Na}_{0.5} \mathrm{Bi}_{0.5} \mathrm{Ti}_{\mathrm{O} 3-} \mathrm{K}_{0.5} \mathrm{~B}_{\mathrm{i} 0.5} \mathrm{Ti}_{\mathrm{O} 3}$ Ferroelectric Ceram- 
ics. Ceramics International, 31, 139-142.

https://doi.org/10.1016/j.ceramint.2004.04.010

[17] Sugimoto, T. (2001) Monodispersed Particles. Elsevier, Amsterdam, 187.

[18] Waseda, Y. and Muramatsu, A. (2003) Morphology Control of Materials and Nanoparticles. Springer, Berlin, 25.

[19] Horn, J.A., Zhang, S.C., Selvaraj, U., Messing, G.L. and Mc Kinstry, S.T. (1999) Templated Grain Growth of Textured Bismuth Titanate. Journal of the American Ceramic Society, 82, 921-926. https://doi.org/10.1111/j.1151-2916.1999.tb01854.x

[20] Kanie, K., Numamoto, Y., Tsukamoto, S., Sasaki, T., Nakaya, M., Tani, J., Takahashi, H. and Muramatsu, A. (2011) Size-Controlled Hydrothermal Synthesis of Bismuth Sodium and Bismuth Potassium Titanate Fine Particles and Application to Lead-Free Piezoelectric Ceramics. Materials Transactions, 52, 1396-1401. https://doi.org/10.2320/matertrans.M2010419

[21] Ballantine Jr., D.S., White, R.M., Martin, S.J., Ricco, A.J., Frye, G.C. and Zellers, E.T. (1997) Acoustic Wave Sensors: Theory, Design, and Physico-Chemical Applications. Academic Press, New York.

[22] Nye, J.F. (1985) Physical Properties of Crystals: Their Representation by Tensors and Matrices. Oxford University Press, London.

[23] Jaffe, B., Cook, W.R. and Jaffe, H. (1971) Piezoelectric Ceramics. Academic Press, New York.

[24] Tani, T. (1998) Crystalline-Oriented Piezoelectric Bulk Ceramics with a PerovskiteType Structure. Journal of the Korean Physical Society, 32, S1217-S1220.

[25] Kanie, K., Sakai, H., Tani, J., Takahashi, H. and Muramatsu, A. (2007) Synthesis of Bismuth Sodium Titanate Fine Particles with Different Shapes by the Gel-Sol Method. Materials Transactions, 48, 2174-2178.

[26] Moulson, A.J. and Herbert, J.M. (2003) Electroceramics: Materials, Properties and Applications. John Wiley \& Sons Ltd., New York. https://doi.org/10.1002/0470867965

[27] Gai, Z.-G., Wang, J.-F., Zhao, M.-L., et al. (2008) The Effect of (Li,Ce) Doping in Aurivillius Phase Material $\mathrm{Na}_{0.25} \mathrm{~K}_{0.25} \mathrm{Bi}_{4.5} \mathrm{Ti}_{4} \mathrm{O}_{15}$. Scripta Materialia, 59, 115-118.

[28] Miyayama, M. and Noguchi, Y. (2005) Polarization Properties and Oxygenvacancy Distribution of $\mathrm{SrBi}_{2} \mathrm{Ta}_{2} \mathrm{O}_{9}$ Ceramics Modified by Ce and Pr. Journal of the European Ceramic Society, 25, 2477-2482.

[29] Xue, D., Zhou, Y., Bao, H., Zhou, C., Gao, J. and Ren, X. (2011) Elastic, Piezoelectric, and Dielectric Properties of $\mathrm{Ba}\left(\mathrm{Zr}_{0.2} \mathrm{Ti}_{0.8}\right) \mathrm{O}_{350}\left(\mathrm{Ba}_{0.7} \mathrm{Ca}_{0.3}\right) \mathrm{TiO}_{3}$ Pb-Free Ceramic at the Morphotropic Phase Boundary. Journal of Applied Physics, 109, 054110-6.

[30] Octonicar, M., Skapin, S.D. and Jancar, B. (2011) TEM Analyses of the Local Crystal and Domain Structure on $\left(\mathrm{Na}_{1-\mathrm{x}} \mathrm{K}_{\mathrm{x}}\right)_{0.5} \mathrm{Bi}_{0.5} \mathrm{TiO}_{3}$ Perovskite Ceramics. IEEE Transactions on Ultrasonics, Ferroelectrics and Frequency Control, 58, 1928-1938. https://doi.org/10.1109/TUFFC.2011.2033

[31] Hooker, M.W. (1998) Properties of PZT-Based Piezoelectric Ceramics between 150 and $250{ }^{\circ} \mathrm{C}$. Technical Report NASA, CR-1998-208708. https://ntrs.nasa.gov/archive/nasa/casi.ntrs.nasa.gov/19980236888.pdf

[32] Karapuzha, A.S., James, N.K., Khanbareh, H., van der Zwaag, S. and Groen, W.A. (2016) Structure, Dielectric and Piezoelectric Properties of Donor Doped PZT Ceramics across the Phase Diagram. Ferroelectrics, 504, 160-171. 